\title{
Izquierda radical, sindicalismo y acción colectiva en Andalucía (1976-2012)
}

\author{
Beltrán ROCA MARTÍNEZ* \\ Universidad de Cádiz \\ Departamento de Economía General \\ beltran.roca@uca.es
}

Recibido: $30-08-2013$

Aceptado: 11-12-2013

\begin{abstract}
RESUMEN
En Andalucía, al igual que en otros puntos de España, se ha configurado un espacio político y sindical de organizaciones de izquierda que se opusieron a la estrategia del PCE, especialmente a partir de los Pactos de la Moncloa. Este artículo analiza los planteamientos, estrategias y evolución del sindicalismo radical en Andalucía desde 1976 hasta 2012 a partir de las diferentes teorías de la acción colectiva. En particular se ofrece un mapeo de aquellos sindicatos radicales influidos por militantes, organizaciones e ideas de izquierda radical, utilizando una perspectiva diacrónica. En primer lugar se describen los principales sindicatos de carácter anarcosindicalista. Posteriormente se examina el amplio espectro de sindicatos de influencia marxista y/o nacionalista andaluz. El sindicalismo radical andaluz no ha logrado desarrollar elementos aglutinantes, identidades compartidas y fórmulas organizativas capaces de disputar la hegemonía de los sindicatos mayoritarios, aunque sí han logrado tener una influencia social significativa en determinados enclaves y momentos. Por último, el artículo identifica los ocho principales factores que explican la implantación del sindicalismo radical andaluz. Para ello, se utiliza una perspectiva sintética sobre los movimientos sociales, que contempla factores políticos, organizativos y culturales.
\end{abstract}

Palabras clave: sindicalismo, izquierda radical, anarcosindicalismo, acción colectiva, Andalucía

\section{Radical left, trade unionism and collective action in Andalusia (1976-2012)}

\begin{abstract}
In Andalusia, as in other parts of Spain, it has been built a political and union space of leftist organisations which opposed the strategy of the Communist Party, especially after the Moncloa Pacts. This article examines the ideas, strategies and evolution of radical trade unionism in Andalusía from 1976 to 2012, using the different theoretical approaches on collective action. In particular it provides a map of those alternative unions influenced by activists, organisations and ideas of the radical left. Firstly, it describes the main anarcho-syndicalist unions. Secondly, it analyses the wide range of Marxist and/or ethno-nationalist trade unions. The history of such organisations is a succession of lost battles, splits, mergers, coordination efforts,
\end{abstract}

* Integrante del grupo de investigación GEISA (Código SEJ-149 del Plan Andaluz de Investigación). Este trabajo se enmarca dentro de un proyecto HAR2012-38837 "Sindicalismo y nuevos movimientos sociales en la construcción de la democracia: España, 1976-2012”, financiado por el Plan Nacional de Investigación del Ministerio de Economía, Innovación y Ciencia 
struggles and small victories. Andalusian radical unionism has not achieved to develop agglutinating agents, shared identities and organisational structures capable of challenging the hegemony of the two majority unions. Nevertheless, it has reached a meaningful social influence and projection in certain territories and moments. Finally, the article suggests the main eight factors which explain the maintenance of the Andalusian radical trade unionism. In doing so it uses a synthetic approach on social movements which includes political, organisational and cultural factors.

Keywords: trade unionism, radical left, anarcho-syndicalism, collective action, Andalusia

\section{REFERENCIA NORMALIZADA}

Roca Martínez, B. (2014) "Izquierda radical, sindicalismo y acción colectiva en Andalucía (1976-2012)". Cuadernos de Relaciones Laborales. Vol. 32, núm. 2, p. 439-468.

SUMARIO: Introducción. 1. El sindicalismo desde las lentes de las teorías sobre la acción colectiva. 2. Organizaciones anarcosindicalistas. 2.1. La reconstitución del anarcosindicalismo en España. 2.2. Confederación Nacional del Trabajo (CNT) en Andalucía. 2.3. Confederación General del Trabajo (CGT) en Andalucía. 3. Sindicatos de clase de influencia marxista y/o etnonacionalista. 3.1. Sindicato de Obreros del Campo (SOC). 3.2. Sindicato Unitario. 3.3. Escisiones de corrientes autogestionarias de la Unión Sindical Obrera en Cádiz. 3.4. Unión de Sindicatos de Trabajadoras y Trabajadores en Andalucía (USTEA). 3.5. Autonomía Obrera. 3.6. Sindicato Obrero Andaluz de la Construcción (SOAC). 3.7. Coordinadora de Trabajadores de Andalucía (CTA). 3.8. Sindicato Democrático de los Trabajadores (SDT). 3.9. Sindicato de Comisiones de Base (CO.BAS). 3.10. Sindicato Andaluz de Trabajadores (SAT). 4. Análisis: un enfoque sintético sobre la acción colectiva del sindicalismo radical. 5. Conclusiones. 6. Glosario. 7. Bibliografía.

\section{Introducción}

En Andalucía como en el resto del Estado las centrales sindicales Comisiones Obreras (CCOO) y Unión General de Trabajadores (UGT) poseen la hegemonía dentro del asociacionismo obrero. Las únicas excepciones son el País Vasco, donde Eusko Langileen Alkartasuna (ELA) es el sindicato mayoritario, y Galicia, donde la Confederación Intersindical Galega (CIG) también tiene el estatus de "sindicato representativo" ". En España existe un modelo de relaciones laborales que los estudiosos denominan "mediterráneo" o de "pluralismo medio". Este sistema se caracteriza por permitir la pluralidad sindical (coexisten varias organizaciones de trabajadores) al mismo tiempo que el Estado establece una serie de mecanismos para seleccionar aquellas a las que se les concede un "plus de representatividad" y, por tanto, mayores capacidades de interlocución, diálogo y financiación (Martin Artiles 2002; García Calavia 2012). En España el criterio elegido para seleccionar estos sindicatos es el número de delegados obtenidos en las elecciones sindicales. A diferencia de otros países, incluso de aquellos que también presentan un modelo similar, el criterio para establecer la representatividad de los sindicatos se basa exclusivamente en la audiencia sindical. Otros países tienen en cuenta además —o

${ }^{1}$ De acuerdo con el marco legal, el estatus de "sindicato representativo" se adquiere obteniendo al menos el 10\% de los representantes en las elecciones sindicales a nivel estatal y el $15 \%$ a nivel autonómico. 
alternativamente - otras variables como la afiliación (base social), la antigüedad o el ámbito territorial, entre otros.

Desde la transición a la democracia hasta hoy en el espacio sindical andaluz han intervenido múltiples organizaciones sindicales minoritarias de carácter radical, cuyos orígenes, estrategias y desarrollos apenas han sido estudiados. En la actual coyuntura de crisis algunas de estas organizaciones están creciendo moderadamente y ampliando su proyección social. Es por esto por lo que su análisis es especialmente oportuno. Este artículo tiene el objetivo de estudiar este sindicalismo radical en Andalucía desde 1976 hasta 2012, prestando atención a sus planteamientos, estrategias y evolución. Para explicar la pervivencia y la acción colectiva de estas organizaciones se contrastarán diferentes teorías sobre los movimientos sociales. De este modo se pretende identificar qué teorías explicativas $\mathrm{y}$, por tanto, qué factores, permiten explicar la existencia de estas organizaciones.

El sindicalismo radical puede definirse como el espacio social formado por aquellas organizaciones obreras que: a) están influidas por ideologías y organizaciones políticas revolucionarias; b) se mantienen al margen de los canales de concertación, apostando principalmente por el conflicto y, en menor medida, la negociación; c) han definido su identidad en oposición a las organizaciones sindicales mayoritarias, de las que critican su falta de democracia interna, su dependencia externa y el bajo nivel de confrontación con los poderes político y económico. Otra característica definitoria del sindicalismo radical en España es su postura crítica respecto a los pactos sociales que dieron lugar a la transición política en la década de los setenta del siglo pasado.

Parte de los pactos de la Transición, precisamente, configuraron el marco que regularía las relaciones laborales. En este sentido destacan los Pactos de la Moncloa de 1977, firmados por las principales fuerzas políticas, incluido el Partido Comunista de España (PCE). Estos acuerdos tenían por objeto, por un lado, sentar las bases para el control de la inflación y la modernización económica del país, y, por otro lado, encauzar las transformaciones en el sistema político (para lo cual era necesario controlar la alta conflictividad laboral de la época). Mientras que el PCE aceptó los Pactos de la Moncloa y, en general, la transición política, apostando por la moderación y la "responsabilidad", un sector de la izquierda rechazó ambos procesos distanciándose del PCE y propugnando una ruptura de mayor calado respecto al régimen franquista (Pérez Serrano 2013). Desde la perspectiva de este sector, la Transición que se estaba desarrollando presentaba demasiadas continuidades y no satisfacía las aspiraciones de cambio, justicia social y libertad de una parte de la población trabajadora. En esa izquierda radical coincidieron tanto tradiciones marxistas fuera del PCE como tradiciones libertarias, aunque la mayor parte del tiempo estas tradiciones se plasmaron en organizaciones diferenciadas.

El sindicalismo radical puede dividirse a su vez en dos grandes grupos: aquellas organizaciones de tipo anarcosindicalista, como la Confederación General del Trabajo (CGT) y la Confederación Nacional del Trabajo (CNT); y aquellas organizaciones de influencia marxista y/o nacionalista andaluz. En el segundo grupo encontramos numerosas organizaciones, la principal de las cuales es el 
Sindicato Andaluz de Trabajadores (SAT), que es la evolución del histórico Sindicato de Obreros del Campo (SOC). Algunas de estas son: Unión Sindical de Trabajadores y Trabajadoras de Andalucía (USTEA), Sindicato Unitario (SU), Autonomía Obrera, Coordinadora de Trabajadores de Andalucía (CTA), Sindicato Unitario Andaluz de Trabajadores (SUAT), Sindicato Democrático de Trabajadores (SDT), Foro Sindical Andaluz (FAS), Comisiones de Base (Co.bas), Sindicato Obrero Andaluz de la Construcción (SOAC) y las escisiones autogestionarias de la USO: Colectivo Autónomo de Trabajadores (CAT), Confederación Libre de Asociaciones de Trabajadores (CLAT) o el Sindicato Autónomo de la $\mathrm{Vid}^{2}$ (SAVID).

Llama la atención que, por diversos motivos (diferencias ideológicas, estratégicas, personales, de ámbito territorial, entre otros), el sindicalismo radical andaluz no ha logrado desarrollar elementos aglutinantes, identidades compartidas y fórmulas organizativas capaces de disputar la hegemonía de los sindicatos mayoritarios. A pesar de ello, estas organizaciones han tenido una influencia social sobre determinadas sectores laborales y formas organizativas muy localizadas que se ajustan al concepto de "particularismo militante" propuesto por David Harvey (Harvey 2007; Roca y Díaz 2013. En muchas ocasiones desplazando a los sindicatos mayoritarios cuya práctica ha descansado en la concertación. También han estableciendo fuertes lazos con movimientos sociales feminista, ecologista, pacifista o alterglobalizador, ampliando el contenido estrictamente laboral de sus luchas y discursos. Para analizar este sindicalismo radical es preciso recurrir a las principales teorías de la acción colectiva. Además, es necesario prestar atención a sus planteamientos, estrategias y evolución ${ }^{3}$. La historia del sindicalismo radical es una sucesión de batallas perdidas, escisiones, fusiones, intentos de coordinación, enfrentamientos y pequeñas victorias, que reflejan la multiplicidad de factores que intervienen en el campo sindical.

${ }^{2}$ En todo caso, SAT y USTEA también reconocen influencias anarquistas o comunistas libertarias en su filosofía. La CTA es, además, una escisión de la anarcosindicalista CGT, aunque en su discurso ya no es posible reconocer la herencia anarcosindicalista.

${ }^{3}$ La información para este estudio procede del análisis de fuentes bibliográficas, documentales (panfletos, estatutos, actas y revistas) y hemerográficas relacionadas con las organizaciones sindicales. Algunas informaciones adicionales han sido obtenidas a través de entrevistas telefónicas con representante sindicales. Asimismo, en algunos casos se ha utilizado información procedente de entrevistas semi-estructuradas realizadas en otros proyectos de investigación en los que he participado con anterioridad. 


\section{El sindicalismo desde las lentes de las teorías sobre la acción colectiva}

En este artículo se pretende explicar la supervivencia e implantación de organizaciones sindicales radicales en Andalucía a través de las teorizaciones sobre la acción colectiva. Al fin y al cabo, fue la eclosión del movimiento obrero lo que empujó a los primeros investigadores sociales a preguntarse por las causas de la acción colectiva. Desde entonces los movimientos sociales han sido estudiados desde diferentes perspectivas de análisis. Los enfoques, además, han estado fuertemente influidos por los contextos desde los que teorizaban los investigadores (Biddle, Graeber y Shuikaitis 2009). Una de las primeras aproximaciones fue la de Mancur Olson (1963), que defendía que los actores sociales participan en movilizaciones y levantamientos según una especie de cálculo coste-beneficio. Sólo cuando los actores sociales perciben que beneficios compensan los costes y riesgos se lanzan a la acción colectiva. Este enfoque - que se conoce como la teoría del comportamiento colectivo - ha sido especialmente utilizado para el estudio del movimiento obrero, aunque fue duramente criticado, especialmente a partir de las movilizaciones del 68 en el que los terrenos de lucha social y las motivaciones parecieron diversificarse (Riechman y Fernández Buey 1994). De este modo, se propusieron nuevos modelos explicativos como la teoría de la movilización de recursos y el paradigma de los nuevos movimientos sociales.

La teoría de la movilización de recursos trata de explicar la acción colectiva no desde el punto de vista individual, sino organizacional. Desde esta perspectiva, los factores clave para el estudio de los movimientos sociales son la estructuración de las organizaciones que promueven la acción colectiva y los recursos de los que disponen. Las organizaciones persiguen finalidades políticas, movilizando apoyos, desplegando estrategias y organizando las actividades (Cucó 2004: 200). Por su parte, la teoría de los nuevos movimientos sociales, desarrollada especialmente en Europa, localizó la mirada sobre los procesos culturales. Para sus defensores, la acción colectiva en las sociedades postindustriales va más allá de los objetivos políticos y económicos y se extienden a las identidades colectivas, a los valores altruistas y a las pautas de sociabilidad. Desde esta perspectiva, las ideologías e identidades compartidas son el factor clave que explica por qué determinados movimientos sociales son capaces de aglutinar apoyos y desarrollar acciones colectivas.

A partir de los años ochenta del pasado siglo, aparecen nuevos enfoques que recogen algunas de las aportaciones de los modelos anteriores. Este es el caso de la teoría del enmarcamiento y la teoría de la estructura de las oportunidades políticas. La teoría del enmarcamiento o frame analysis pone el énfasis en cómo los movimientos generan sus propios marcos de referencia, es decir, las "ideologías, identidades colectivas, rutinas de comportamiento y culturas materiales" (McAdam 1994: 54). El objetivo de esta aproximación es comprender los marcos interpretativos construidos por los participantes de los movimientos sociales para legitimar y llevar a cabo la acción colectiva. La perspectiva de la estructura de las oportunidades políticas, en cambio, propone centrarse en los cambios en el contexto 
político que hacen posible los fenómenos de protesta. Para Sydney Tarrow (1998) existen dos bloques de oportunidades políticas: los elementos estables (entre los que destaca la forma de Estado) y los elementos variables (el grado de apertura del sistema político, los cambios en las alianzas de los sectores dominantes, la existencia de aliados influyentes y el conflicto entre las élites). Tarrow (1998) o Della Porta (1998), por ejemplo, utilizan este esquema para explicar diferentes tipos de movimientos sociales y revoluciones en contextos históricos y geográficos muy distintos.

Teorías posteriores han criticado a estos enfoques su excesivo mecanisicmo y reduccionismo. Los movimientos sociales no pueden ser vistos como entidades homogéneas, pues son portadores de contradicciones internas y protagonizan constantes fluctuaciones. Además, bajo la categoría "movimiento social" se recoge tal heterogeneidad de realidades que con frecuencia no se ajustan a los modelos ideales construidos por los investigadores. Esto es especialmente evidente en el actual contexto de globalización en el que el escenario de la acción colectiva se complejiza notablemente (Escobar 1992; Melucci 1994). Por ello, algunos investigadores apuestan por acercamientos de tipo etnográfico (Juris 2008) y recomiendan un tipo de acercamiento que los defina en sus propios términos (Castells 1998).

Cada teoría ha puesto el acento sobre diferentes factores explicativos de un mismo fenómeno. En este análisis del sindicalismo radical en la comunidad andaluza se utilizará una perspectiva sintética. El objetivo de este artículo es conocer qué enfoques - $\mathrm{y}$, por tanto, factores - sirven para explicar la implantación, la evolución y actuaciones de estas organizaciones. Como han afirmado McAdam, McArthy y Zald (1996:2-6), la acción colectiva depende de tres factores: las formas de organización, la estructura de oportunidades políticas y los procesos de interpretación y construcción de identidades.

\section{Organizaciones anarcosindicalistas}

\subsection{La reconstitución del anarcosindicalismo en España}

Aunque el histórico sindicato anarcosindicalista CNT había operado en la clandestinidad durante la dictadura, no será hasta la muerte de Francisco Franco cuando se reorganice aprovechando, al igual que el resto de fuerzas sociales de la izquierda, el nuevo escenario político. Así a partir de diciembre de 1975 se van sucediendo reuniones de militantes que van reconstituyendo Confederaciones Regionales en diferentes puntos del Estado. En julio de 1976 se crea el primer Comité Nacional y se vuelve a publicar el periódico "cnt". En esos años se desarrolla un intenso trabajo de reorganización, formación de militantes, contactos con otras fuerzas sindicales (especialmente UGT) y actividad de protesta (como la reivindicación de la libertad sindical, la oposición al recientemente aprobado despido libre y la congelación salarial). 
En 1977 se intensifica la actividad sindical con la participación de CNT en luchas significativas como las de Roca, Tarabusi, Induico o el diario "Pueblo". Además, se realizan numerosas acciones con el objeto de recuperar el Patrimonio Histórico y Acumulado, procedente de la CNT antes de la guerra y del Sindicato Vertical con la cuota obligatoria de los trabajadores durante el franquismo, respectivamente. El sindicato también aumenta su capacidad de convocatoria, como el Mitin en San Sebastián de los reyes (Madrid) que aglutina inesperadamente a unas 30.000 personas. El 7 de mayo de ese año, Juan Gómez casas y Pedro Barrios Guazo inscriben la documentación de CNT en el registro del Ministerio, legalizando así al sindicato. Dos meses más tarde el sindicato celebró el histórico mitin de Montjuïc, que aglutinaría a unas 50.000 personas y en el que hablaron Enrique Marcos, José Peirats, Federica Montseny, Fernando Piernavieja y Antonio Morales, entre otros. En dicho mitin se reflejaron las diferentes tendencias y sensibilidades que estaban configurando el sindicato. Pocos días después del Mitin, CNT organiza las Jornadas Internacionales Libertarias, como gran afluencia y que tuvieron gran relevancia para la implantación del sindicato y su estrategia social y sindical. En Andalucía en dicho periodo la CNT contaba con 60 federaciones locales y su publicación propia, “Andalucía Libertaria” (Vadillo 2004).

En octubre de 1977 las fuerzas políticas acuerdan los Pactos de la Moncloa, encaminados a controlar la inflación económica y sentar las bases del sistema político que se estaba gestando. En el plano sindical, CCOO manifestó su apoyo. UGT mantuvo al principio una postura crítica, aunque posteriormente respaldaría dichos acuerdos. Sólo CNT se mantuvo crítica e impulsó movilizaciones en contra.

En un contexto de atentados terroristas por parte del GRAPO y la extrema derecha, el movimiento libertario y la CNT también aparecen como blanco de la represión estatal, a pesar de que el sindicato, en sus comunicados, se había desvinculado totalmente de cualquier acto terrorista. Sin embargo, la actitud crítica del sindicato frente al proceso de transición en general, y los Pactos de la Moncloa en particular, provocaron que la CNT fuera objeto de maniobras policiales y de los medios de comunicación encaminadas a desprestigiarla y deteriorar su imagen pública. El acontecimiento más notorio fue el extraño incendio de la sala de espectáculos Scala de Barcelona tras una manifestación convocada por CNT en 1978, que se saldó con cuatro trabajadores muertos. A pesar de comprobarse la implicación de infiltrados policiales en el suceso, y de la condena del atentado por parte de los Comités del sindicato. Hubo una intensa campaña mediática de desprestigio.

A pesar los obstáculos, el sindicato avanzaba. Se estaba participando activamente en duras luchas laborales, entre las que destacó la huelga de gasolineras de la provincia de Barcelona y, en Andalucía, las luchas en los astilleros de Cádiz. La llamada del sindicato a la abstención en las primeras elecciones sindicales de 1978 tuvo cierto efecto en las tasas de participación (Vadillo 2004: 10).

A partir de 1979 las divisiones internas, favorecidas por la gran diversidad de tendencias ideológicas y programáticas que confluían bajo las siglas de una organización que no había terminado de definir su estrategia, terminaron por 
fracturar a CNT. En el V Congreso de diciembre de 1979 se produce la primera escisión, promovida por el Comité Nacional al sentirse agraviado por no aprobarse su informe de gestión. Durante este congreso, un sector denuncia que el evento se ha desarrollado bajo presiones y amenazas. Criticaban que no se hubiera permitido al Comité Nacional gestionar el Congreso. Por ello, un gran número de sindicatos decide abandonar la organización ${ }^{4}$.

En 1980 los escindidos organizan su propio congreso en Valencia, al que asisten 300 delegados en representación de alrededor de 100 sindicatos. Este sector nombra como secretario general a Carlos Martínez y aprueba la participación en las elecciones sindicales con el objeto de no mantener al sindicato en una posición marginal en el ámbito de las relaciones laborales. Este sector se denominó CNTcongreso de Valencia y comenzaría una pugna por el derecho al uso de las siglas que no se resolvería hasta 1989.

En 1982 el otro sector, encabezado por José Bondía, celebró el VI Congreso en Barcelona en enero de 1983. José Bondía y un sector de CNT aún se mostraba favorable a la participación en las elecciones sindicales, por lo que la cuestión quedó nada resuelta y tuvo que celebrarse un congreso extraordinario en Torrejón de Ardoz en marzo-abril de ese mismo año. El punto más polémico fue el de las elecciones sindicales y la acción sindical en la empresa. La correlación de fuerzas entre los partidarios y detractores de la participación en las elecciones estuvo muy igualada, sin embargo, finalmente se aprobó la oposición a las elecciones sindicales y comités de empresa. El sector favorable a las elecciones abandonó el sindicato tras el congreso. Muchos de ellos se unieron a la CNT-Congreso de Valencia. En 1984 celebraron un Congreso de Unificación al que asistieron 184 sindicatos, formando la CNT-Renovada, partidaria de presentarse a las elecciones sindicales. Este sector, en 1989, tras una polémica sentencia judicial por el uso de las siglas, adoptó el nombre de Confederación General del Trabajo (CGT).

\subsection{Confederación Nacional del Trabajo (CNT) en Andalucía}

En Andalucía, al igual que en el resto del Estado, la CNT se vio muy afectada por las escisiones. Además, la no participación en las elecciones sindicales no vino acompañada de una estrategia efectiva de inserción en las empresas, quizá por la mezcla de planteamientos autonomistas y espontaneístas con genuinamente anarcosindicalistas. Los núcleos que quedaron en el sindicato centraron su actividad más en la propaganda política que en la acción en la empresa. Las mayores luchas de CNT en la década de los noventa del siglo pasado se dieron en el sector de la construcción naval (principalmente en el astillero de Puerto Real) y en el sector agrario en la sierra sur de Sevilla.

En el astillero de Puerto Real, desde la reconstitución del sindicato funcionó Sección Sindical de CNT —encabezada por Pepe Gómez, Francisco Aragón o Juan

\footnotetext{
${ }^{4}$ Bicileta $\mathrm{n}^{\circ}$ 23, diciembre de 1979, citado en Vadillo 2004.
} 
Ceballos, entre otros, en diferentes momentos- que tuvo una marcada influencia entre la plantilla y en la comarca. La Sección de CNT en el astillero contribuyó a la radicalización de las luchas laborales del astillero y su extensión a la sociedad local (Florido, Roca y Gutiérrez 2013; Pérez de Guzmán 2012). Especialmente en los diversos procesos de reconversión industrial que amenazaban la supervivencia del astillero, la CNT impulsó dinámicas asamblearias y acciones directas. Esta Sección logró el reconocimiento de derechos que la Ley Orgánica de Libertad Sindical ${ }^{5}$ sólo reconoce a los sindicatos que participan en las elecciones sindicales. La Sección llegó a tener más de un centenar de afiliados en la factoría y aún hoy, aunque la empresa cuenta sólo con 600 trabajadores y la Sección de CNT tiene sólo una veintena de afiliados, el sindicato goza de un gran prestigio en el municipio y ha influido en la configuración de una "cultura sindical" asamblearia y combativa entre los trabajadores del sector ${ }^{6}$ (incluida la empresa auxiliar, que es la que emplea hoy a la mayor parte de los trabajadores).

En el campo andaluz, a pesar de la fuerte herencia anarcosindicalista que el franquismo nunca consiguió erradicar, la hegemonía sindical fue adquirida en la Transición por las Comisiones Obreras del Campo, más moderadas, y el Sindicato de Obreros del Campo, más radical. CNT tan sólo logro desarrollar núcleos en algunos puntos del Sur de Sevilla, como Arahal, Utrera y, sobre todo, Pedrera. La histórica reivindicación de la Reforma Agraria recobró vigencia en el movimiento jornalero en la Transición, y con el horizonte del reparto de la tierra y el fin del latifundismo, los trabajadores del campo llevaron a cabo importantes movilizaciones. En 1977 CNT promueve su primera huelga entre los olivareros del Sur de Sevilla. No obstante, en 1990-1991, a través de la Asamblea Permanente de Jornaleros en Huelga, CNT con el apoyo del SOC y CCOO, llegó a paralizar el trabajo agrícola 40 días, extendiendo la huelga desde Pedrera a toda la provincia de Sevilla, e incluso algunos puntos de Córdoba y Málaga. El paro laboral estuvo acompañado de otras acciones radicales como el encierro en ayuntamientos, el corte de carreteras y la ocupación de fincas. Esta lucha consiguió reivindicaciones relevantes como reducción de la jornada laboral, igualdad entre hombres y mujeres en relación a la contratación, aumento salarial, mejor reparto del trabajo en el Plan de Empleo Rural y la eliminación de las peonadas para cobrar el subsidio agrario.

Con excepción de estas dos luchas localizadas, CNT quedó relegada a un lugar marginal dentro del mundo de las relaciones laborales en España y Andalucía. No será hasta principios del siglo XXI cuando el sindicato vaya definiendo estrategias

${ }^{5}$ Ley Orgánica 11/1985 de Libertad Sindical, que sienta las bases del sistema sindical español.

${ }^{6}$ No es casualidad que el Convenio del Metal de la provincia de Cádiz sea uno de los mejores convenios de España, no sólo en materia salarial sino también en derechos sociales y sindicales. 
para revertir esa situación ${ }^{7}$. En el año 2001 CNT comienza a desarrollar nueva actividad sindical en todo el Estado, aunque la confederación andaluza es una de las que más despega con conflictos con empresas como Paradores, Minit Colors (extensión de un conflicto del Sindicato de Artes Gráficas de Madrid), FAISEM, entre otros. En 2002 el sindicato inicia una huelga en la empresa de recogida de Residuos Sólidos Urbanos de Tomares (Sevilla). Al año siguiente se repetiría la huelga en el mismo servicio por el incumplimiento de lo pactado. Esta nueva huelga duraría 134 días. Estas experiencias de lucha laboral entusiasman a una parte de la nueva afiliación y sirven para fomentar la formación y el interés en la actividad sindical. A partir de esas fechas CNT organiza numerosos grupos de trabajadores, constituye Secciones Sindicales, convoca huelgas, se dota de buenos servicios jurídicos y experimenta un significativo aumento de afiliación y actividad. Este desarrollo, no obstante, es visto con recelo por una parte de un sector de la militancia, que desea una organización con un contenido político más explícito y una afiliación exclusivamente libertaria ${ }^{8}$. A pesar de las diferencias internas, el sindicato sigue creciendo llegando a convocar en solitario una huelga general de 24 horas en Lebrija en 2008 por el reparto del trabajo, acceder a la negociación colectiva en algunas empresas o impulsar movilizaciones de parados. El X Congreso Confederal celebrado en Córdoba en 2010 refleja la hegemonía del sector que defiende un sindicato abierto y se abre la vía a la coordinación con otros sindicatos radicales. Hoy CNT cuenta con sindicatos en alrededor de 20 municipios y ha aumentado de 400 a 1000 afiliados en la comunidad autónoma en la última década.

${ }^{7}$ Algunos secretarios generales de los últimos años son Julio Álvarez, Juan Ceballos y Pasión Pineda. Destaca, asimismo, la infatigable actividad de José Luis García Rúa desde el sindicato de Enseñanza de Granada.

${ }^{8}$ En ocasiones estos militantes utilizan como modelo la Federación Obrera Regional Argentina (FORA) V Congreso, una escisión de la FORA — un sindicato revolucionario argentino fundado en 1901-, que en 1915, en su IX Congreso, decidió eliminar de sus estatutos la adhesión a la finalidad del anarquismo. La FORA V Congreso, liderada por Diego Abad de Santillán y Emilio López Arango, tuvo una notable influencia en Argentina hasta los años 30 del pasado siglo. La dictadura militar y la incapacidad para adaptarse a los nuevos marcos legislativos han mantenido a dicha organización en un lugar marginal desde entonces. La cuestión es que hoy estos militantes de CNT son partidarios de un "movimiento obrero anarquista", es decir, un sindicato para los anarquistas, mientras que el otro sector, propiamente "anarcosindicalista", defiende un modelo sindical abierto a todos los trabajadores pero con finalidades e influencias libertarias (combinando el sindicalismo revolucionario y el anarquismo al modo de la CNT histórica). 


\subsection{Confederación General del Trabajo (CGT) en Andalucía}

Como hemos visto, a partir de 1989 la CNT-Renovada adquiere el nombre de CGT. Este sindicato es hoy el sindicato radical estatal de mayores dimensiones. Afirman tener 80.000 afiliados en toda España. A pesar de participar en las elecciones sindicales y recibir subvenciones del Estado (que es lo que diferencia principalmente a CGT de CNT), preserva su identidad y su discurso anarcosindicalista, y mantiene estrechas relaciones con movimientos sociales (desde el ecologismo hasta el 15M).

En Andalucía, la CGT ha mantenido un crecimiento sostenido. Según la Consejería de Empleo, en las elecciones sindicales del año 1994/1995 obtuvieron 75 delegados, en 2003 obtuvieron 243 y en 2011 llegaron casi a 300 (aunque ampliando el periodo entre 2009-2011 obtuvieron 522 delegados), la mayor parte de éstos en Málaga, Cádiz y Sevilla. Esto convierte a CGT en el sindicato radical con más implantación en las empresas en Andalucía. La presencia territorial del sindicato es irregular, principalmente se encuentra en núcleos urbanos (a excepción del municipio sevillano Martín de la Jara en la que han constituido un sindicato local a partir de trabajadores descontentos con el SOC). Hay que recordar que el espacio del sindicalismo radical agrario andaluz fue ocupado estratégicamente por el SOC en la Transición y lo ha mantenido desde entonces. De este modo, CGT es un sindicato que funciona principalmente en sector de servicios públicos (como sanidad, educación, transporte, limpieza y administración local) y, en menor medida, en la gran industria (como Delphi, Airbus, Acerinox). Desde esta perspectiva, el ámbito de desarrollo de CGT no se diferencia mucho del de los sindicatos mayoritarios (grandes empresas, con alta concentración de trabajadores en las que es posible celebrar elecciones sindicales).

CGT tiene sedes en las ocho capitales de provincia en Andalucía, generalmente haciendo uso de locales de Patrimonio Sindical Acumulado (procedentes del "sindicato vertical" franquista). En menor medida, tiene locales en algunos municipios grandes como Chiclana, Motril-Costa de Granada, Jerez o Campo de Gibraltar). Algunos secretarios generales de la CGT en Andalucía en los últimos años han sido Agustín Gómez Acosta y Pepe García Rey (aunque en ocasiones, a causa de dimisiones de secretarios generales, han adoptado sus funciones secretarios de organización como Félix Cervera o Thulio Moreno Gómez).

En ocasiones CGT ha recibido grandes cantidades de trabajadores descontentos con los sindicatos mayoritarios (sobre todo de CCOO). También ha sufrido escisiones como la del sindicato CTA, que se describirá más adelante, o del Sindicato Andaluz de Conductores (SAC), creado en 2008 a raíz de trabajadores de Transportes Generales Comes, como Pepe Morales, Antonio Jiménez o Francisco Ortiz, que salieron desencantados con el funcionamiento del sindicato a raíz de sus actuaciones durante la lucha por el convenio de la empresa. El SAC se extendió por el sector de transporte de viajeros por carretera, especialmente por Cádiz y Sevilla y en menor medida Málaga. En Sevilla, por ejemplo, incorporaron a los afiliados y delegados de la Asociación Sindical de Conductores (ASC) de la empresa Casal. Hoy siguen manteniendo relaciones con CGT y CNT. 
Las relaciones entre CGT y el sindicalismo radical en Andalucía han sido de colaboración aunque también de rivalidad. Ha colaborado estrechamente con el SOC, USTEA o el SU, aunque, a pesar de los intentos de coordinación, nunca se han dado pasos firmes hacia una fusión entre estas organizaciones. Con CNT las relaciones han sido más tensas a causa de la rivalidad por el uso de las siglas, el patrimonio histórico y las señas de identidad. Sin embargo, el cambio de actitud de CNT a partir de su X Congreso, celebrado en Córdoba en diciembre de 2010, ha propiciado un clima de colaboración y respeto.

\section{Sindicatos de clase de influencia marxista y/o etnonacionalista}

Algunos de los sindicatos radicales de carácter marxista presentes en Andalucía provienen de un sector de la izquierda que se definió en oposición al PCE durante la lucha contra el franquismo ${ }^{9}$. En concreto, en el tercer Pleno del Comité Central de dicho partido, en 1957, se fue consolidando una línea moderada de la que se distanciaría el sector más radical de la izquierda, que iría constituyendo sus propias organizaciones políticas y, en ocasiones, sus propios sindicatos. Estas iniciativas, por lo general, cosecharon escasos éxitos y las organizaciones tuvieron en no pocos casos una vida efímera. A continuación se va a exponer la evolución de dichas organizaciones por orden cronológico.

\subsection{Sindicato de Obreros del Campo (SOC)}

En 1967 surge el PCE(i) como escisión al PCE por parte de militantes aglutinados en torno a la revista Unidad. Esta organización política se extiende por España pero rápidamente sufre escisiones, como Bandera Roja en 1968, Partido Comunista de España Internacionalista en 1969 y Partido Comunista de España Internacional línea proletaria en 1970. Entre 1972 y 1973 se reagrupa.

En Andalucía, el PCE(i) se expandió a partir de un núcleo inicial de profesionales y estudiantes de Sevilla, llegando a ocupar en varios municipios un espacio político que el PCE y CCOO había dejado vacío, como Villamartin o El Coronil. En 1975 el PCE(i) cambia de nombre a PTE (Partido del Trabajo de España). En pocos años llega a ser la mayor organización de la izquierda radical a la izquierda del PCE en el campo andaluz. Sus militantes provenían principalmente de dos fuentes: por un lado, recibió numerosos militantes del PCE desencantados

\footnotetext{
${ }^{9}$ Tampoco hay que olvidar que una parte de estas organizaciones fueron impulsadas por un sector de la iglesia Católica, comprometido con el movimiento obrero y la lucha antifranquista. Este fue el caso de la HOAC (Hermandad Obrera de Acción Católica) y la JOC (Juventud Obrera Cristiana), que nutrieron y apoyaron a los sindicatos durante la transición política.
} 
con la línea oficial del partido; por otro lado, la organización estudiantil Joven Guardia Roja también contribuyó a ampliar las bases en el mundo universitario.

En 1975, mientras en el resto del Estado español los militantes del PTE militaban en $\mathrm{CCOO}$, en Andalucía los militantes crearon su propio sindicato jornalero: las Comisiones de Jornaleros. En 1976 a nivel estatal el PTE decidió constituir su propia organización sindical como parte de su estrategia de disputar la hegemonía del PCE. De este modo constituyeron la CSUT, a la que se adheriría el Sindicato de Obreros del Campo, SOC (nombre que habían adquirido las Comisiones de Jornaleros en su congreso en Antequera en agosto de ese año). El SOC, sin embargo, no se terminaría de constituir hasta 1977, en el congreso de Morón. El nuevo sindicato se extendió por el medio rural andaluz, aunque su mayor zona de implantación fue le Sierra de Cádiz y la Sierra Sur de Sevilla, donde mantuvieron la tradición de lucha por el reparto del subsidio agrario y otras reivindicaciones de carácter más radical ${ }^{10}$.

En las elecciones generales de 1977 el PTE fracasó, aunque en las municipales en Andalucía el PTA (Partido del Trabajo de Andalucía) y las CUT (Colectivo de Unidad de los Trabajadores) lograron numerosas alcaldías en municipios de Córdoba, Cádiz, Granada y, especialmente, Sevilla. La fusión entre el PTE y la ORT (Organización Revolucionaria de Trabajadores, de carácter maoísta) no logró evitar el fracaso electoral de 1979. El PCE había consolidado su hegemonía en la izquierda. Esto provocó una crisis en los aparatos político y sindical. La CSUT obtuvo solamente el 3,4\% de los votos en las elecciones sindicales de 1978, con 399 delegados. En las elecciones de 1980 el número de delegados se redujo a 33. El SOC, en su II congreso, celebrado en Puebla de Cazalla en 1980, se desvinculó de la CSUT. En 1983 el PTA sufrió un nuevo revés. Tras la victoria del PSOE en las elecciones generales de 1982, numerosos alcaldes del PTA se pasaron al PSOE. Esto afectó duramente al movimiento sindical, puesto que había dedicado a sus mejores cuadros a la conquista del poder político. Así, entró en crisis el modelo "partido-sindicato" (Morales Ruiz 2000).

En la década de 1980 el SOC mantiene su actividad, mientras el CSUT se termina integrando en $\mathrm{CCOO}$ y el SU iban desapareciendo. Las claves de la supervivencia del SOC en los años 80 y 90 del siglo XX son: el mantenimiento del discurso nacionalista andaluz de clase; la ocupación temprana que hizo de un espacio que el resto de la izquierda había dejado vacío (el de los jornaleros); su carácter de movimiento social autónomo; el carisma de sus líderes (Diamantino García, Francisco Casero, Juan Manuel Sánchez Gordillo o Diego Cañamero); y el respeto a las particularidades locales (Morales Ruiz 2000: 193) (además de la heterogeneidad ideológica interna).

10 Sobre la importancia del subsidio agrario en la movilización del SOC y su implantación en el municipio sevillano de Marinaleda, ver Talego (1996). 
Así, el SOC mantuvo en el tiempo su actividad reivindicativa. Por ejemplo, Gómez Oliver ha analizado a través de la prensa la conflictividad entre 1983 y 1988 , identificando 1.654 acciones reivindicativas. La modalidad más practicada en todo el periodo fueron los encierros (28\%), sobre todo iglesias, sedes sindicales y Ayuntamientos. El segundo tipo de protesta fueron las ocupaciones de fincas $(24,4 \%)$, la mayor parte de éstas temporales, con carácter simbólico, pero en las que participaba el pueblo entero y se apuntaba al problema central: la tenencia de la tierra (Gómez Oliver 1993). El principal objetivo de las protestas fue el Plan de Empleo Rural (43,5\%), seguido de acciones de solidaridad contra la represión de líderes $(25 \%)$ y, más de lejos, la reivindicación de la tierra (18\%). El desplazamiento del objetivo de la redistribución de la tierra es interpretado por varios autores como un signo de la creciente debilidad del movimiento jornalero (Gómez Oliver 1993; Solana Ruiz 2000).

En los años 90 y 2000, la conflictividad jornalera descendió notablemente. El SOC ha afirmado mantener una afiliación de 20.000 trabajadores. En estos años preservó su poder institucional participando en la gestión del PER, pero con ello también se convirtió en partícipe del desvío de objetivos y de la pérdida de identidad de los jornaleros.

\subsection{Sindicato Unitario}

Los orígenes de este sindicato se remontan a la competencia entre el PCE y la Organización Revolucionaria de Trabajadores ${ }^{11}$ (ORT), por la hegemonía dentro de CCOO. Durante el franquismo, las CCOO habían adoptado la estrategia de copar las estructuras del "sindicato vertical", a diferencia de otras organizaciones sindicales históricas, como CNT o UGT, que apostaban por desarrollar su acción desde fuera. Esa estrategia facilitó la extensión de CCOO y su hegemonía en las primeras elecciones sindicales de la democracia de 1978.

En Huelva, a mediados de los setenta del siglo pasado la corriente hegemónica dentro de CCOO fue la de la ORT, encabezada por los militantes Juan Ceada y Luis Ramos. No obstante, el PCE poco a poco iría ganando terreno en la provincia, encabezados por Venancio Cermeño. La corriente de la ORT tan sólo sería mayoritaria en la capital onubense. Cada corriente tenía sus propias publicaciones y multicopista, pero actuaban de manera unitaria.

A nivel estatal, sin embargo, la rivalidad entre la ORT y el PCE por el control sobre CCOO se resolvería a favor del PCE. La ORT abogaba por una lucha político-sindical mientras que el PCE defendía separar la lucha sindical de la política, para así moderar el movimiento obrero de cara a los pactos que se estaban celebrando entre las fuerzas políticas. Así, la ORT decidió en 1977 fundar su propio

${ }^{11}$ La ORT fue un partido marxista leninista de línea maoísta, creado en 1969 a partir de la organización Acción Sindical de Trabajadores formada por militantes socialistas católicos de la HOA, la JOC y Vanguardia Obrera, más radicalizados (Feria Vázquez 2005). 
sindicato, el Sindicato Unitario, que con el tiempo iría afiliando a trabajadores y delegados descontentos con los sindicatos mayoritarios. En Huelva, ya en 1976 unos 500 trabajadores de la factoría de Fosfórico Español decidieron crear su propia organización sindical de empresa, el Sindicato de Obreros del Fosfórico. A ellos se unieron trabajadores de otros sectores y empresas de la provincia. El 10 de mayo de 1977 se integraron en el Sindicato Unitario, de ámbito estatal.

El Sindicato Unitario en Andalucía cosechó un éxito considerable en las elecciones sindicales de 1978, en las que obtuvo 848 delegados, especialmente en Huelva, su principal bastión, donde tenía importante afiliación y representación en sectores, como el químico, el metal, la banca, la sanidad, la construcción, el comercio, la hostelería y la agricultura. A mediados de los años 80 fue perdiendo fuerza, tanto en Huelva como en todo el Estado. Hoy sólo quedan núcleos en Huelva, Madrid, Cantabria y Cataluña (donde tienen representación en el metro de Barcelona). En las elecciones sindicales de 2011 sólo obtuvieron 33 delegados en la provincia de Huelva (60 delegados en el periodo 2009-2011). En Andalucía tienen actividad principalmente en el Polo Químico, en las refinerías de La Rábida (CEPSA) y Palos de la Frontera (ERTISA), en el campo (principalmente entre los temporeros de la fresa), y algo menos empresas como EMTUSA (encargada del servicio de transporte urbano de viajeros). Bajo la secretaría de Miguel Cano, a principios del siglo XXI, ha llevado a cabo un intenso trabajo de denuncia de la situación de los temporeros inmigrantes en Huelva en la recogida de la fresa junto al sindicato CGT.

\subsection{Escisiones de corrientes autogestionarias de la Unión Sindical Obrera en Cádiz}

La Unión Sindical Obrera (USO) se fundó en 1960 por parte de militantes provenientes de la JOC y la HOAC. Sus señas de identidad eran la combinación de valores socialistas y católicos. Uno de los bastiones de la USO en España fue la provincia de Cádiz, donde había un fuerte movimiento obrero que operaba desde dentro de la Iglesia Católica, con líderes como Esteban Caamaño o Isidro Gálvez. Por ejemplo, entre 1973 y 1983 fuentes del registro del gobierno civil de Cádiz reflejan que el $70 \%$ de las asociaciones inscritas pertenecieron a dicho sindicato (Piñeiro Blanca 2009).

Aunque ya entre 1969 y 1970 hubo escisiones en la USO por parte de sectores cercanos al trotskismo y el consejismo en Asturias, Valencia y Valladolid, en 1977 sufrió una dura escisión en la que sus principales dirigentes se pasaron a UGT, decepcionados por el resultado de las elecciones generales. En 1978, con Manuel Zaguirre a la cabeza, los militantes tratan de reorganizar el sindicato, refundando su identidad y valores, lo que origina nuevas tensiones internas (Montes Pita 2009). Una de las decisiones más polémicas fue la de incorporar a representantes independientes, aprobada en el VII Consejo Confederal en de 1978. Esta decisión era percibida por parte de las bases como una derechización del sindicato, pues muchos de estos independientes provenían de partidos de derecha y del antiguo Sindicato Vertical. Así, el sindicato se va dividiendo en dos facciones: una más 
moderada que abogaba por la concertación, las relaciones con todas las fuerzas políticas democráticas y hacer un bloque con UGT, y otra más crítica, con fuerte componente socialista autogestionaria ${ }^{12}$ (algunos de ellos relacionados con la editorial ZXY). En marzo de 1980, encabezados por José Corell, abandona la organización enfrentados con la dirección y se deciden integrarse en CCOO. Sólo algunos núcleos autogestionarios salidos de USO se niegan a integrarse en CCOO. En el Marco de Jerez, estos militantes constituyen la Confederación Libre y Autónoma de Trabajadores (CLAT), cuyo principal sindicato era el Sindicato Autónomo de la Vid (SAVID). En el astillero de Puerto Real, encabezados por el sindicalista Pepe Zorilla, constituyeron el Colectivo Autónomo de Trabajadores con implantación en el sector de la construcción naval (en los tres astilleros de la Bahía de Cádiz, Puerto Real, San Fernando y Cádiz). El CAT sigue teniendo hoy algunos representantes en dichos astilleros además de en la empresa auxiliar. Según datos de la Consejería de Empleo, en las elecciones sindicales de 2011 obtuvieron 12 delegados en el sector de la construcción naval en la provincia de Cádiz.

En el Marco de Jerez, el SAVID protagonizó duras luchas por los convenios colectivos y contra la regulación de empleo en los sectores bodeguero y vitivinícola. En este sindicato destacaron dirigentes como José María Gaitero Rosado o Sebastián González. A finales de los años ochenta, la mayor parte del SAVID termina integrándose en CCOO. Otro sector, en el que destacaba el sindicalista Juan Conde Orellana, se integraría en la CGT.

\subsection{Unión de Sindicatos de Trabajadoras y Trabajadores en Andalucía (USTEA)}

USTEA es un sindicato que se define como asambleario y de izquierdas implantado en el ámbito del sector público andaluz. Este sindicato es la evolución de las asambleas de docentes que se extendieron por todo el Estado durante los últimos años del franquismo al margen del "sindicato vertical" (el Servicio Español de Maestros). Iniciada la transición y reconocida la libertad sindical, estas asambleas provinciales de docentes constituyeron en 1977 la Unión Confederal de Sindicatos de Trabajadores de la Enseñanza (UCSTE). Durante la década de los ochenta esta organización sufrió una escisión entre una facción más izquierdista y otra más moderada. En 1990 se reunifican ambas facciones y denominan al nuevo sindicato Confederación de STEs (Sindicatos de Trabajadores de Enseñanza).

USTEA, como estructura andaluza de STEs, ha defendido la revisión del Concordato entre el Estado español y el Vaticano y el carácter público de la enseñanza. Algunos de sus militantes pertenecen al Movimiento de Renovación Pedagógica, unos colectivos autónomos que persigue la implicación ética y política del profesorado en pro de educación pública y orientada justicia social y la

\footnotetext{
${ }^{12}$ Testimonio de Manuel Zaguirre respecto a la escisión de USO de 1977 (Martín Artiles 1987: 48)
} 
humanización (Rogero 2010). Además, en Andalucía ha defendido la unidad de acción con el sindicalismo radical, por ejemplo, impulsando la Mesa Intersindical Andaluza junto al SUAT, el SOC y el Sindicato Unitario a finales de la década de los noventa del siglo pasado.

Aunque USTEA inicialmente estuvo formado por trabajadores de la enseñanza, con el tiempo se extendió a la sanidad y la administración. Su mayor implantación se da entre el profesorado de educación pública de primaria y secundaria, sector en el que ha logrado disputar la hegemonía de CCOO y UGT. De hecho, USTEA está experimentando un crecimiento significativo en términos de representación sindical. En las elecciones sindicales de 2003 obtuvieron 71 delegados en Andalucía, y en 2011 lograron 163 delegados (en el periodo 2009-2011 la cantidad ascendió a 232 dlegados). Al estar muy concentrados en el área de enseñanza pública, tienen representación en la mesa sectorial y otros espacios de diálogo con la Administración.

USTEA, junto con el Sindicato Ferroviario, forma en Andalucía la Intersindical Andaluza-Confederación, federación en esta comunidad autónoma de la Confederación Intersindical, constituida en noviembre de 2007 aglutinando en el ámbito estatal a STEs y al Sindicato Ferroviario.

\subsection{Autonomía Obrera}

Autonomía Obrera nace en 1997 en Cádiz por parte de una serie de representantes sindicales de $\mathrm{CCOO}$ que formaban parte de la corriente izquierda sindical. Izquierda sindical era un sector de $\mathrm{CCOO}$ formado por militantes de organizaciones de izquierda radical LCR (Liga Comunista Revolucionaria), de línea trotskista, MC, línea maoísta ${ }^{13}$, y Bandera Roja. Esta facción de CCOO se oponía a la política de la dirección del sindicato en tres frentes: el énfasis en la concertación social, descuidando la combatividad; la falta de democracia interna; y el apoyo acrítico a las políticas antiterroristas del Estado, sin reconocer el derecho de autodeterminación de los pueblos. En los años 1997 y 1998 CCOO expulsó a numerosos militantes de este sector, algunos de los cuales constituyeron sus propias organizaciones sindicales o se sumaron a otros sindicatos radicales existentes. En Cádiz, el asesinato del concejal del PP Miguel Ángel Blanco en 1997 fue el detonante de las expulsiones. Representantes de CCOO gaditanos, como José Martínez Caño (Hospital Puerta del Mar), Vicente Delgado García (Diputación), José Manuel Casas (Servicio Andaluz de Salud), Carmen Pérez (Tabacalera) y representantes sindicales del Ayuntamiento de Cádiz, firmaron un comunicado en apoyo a la formación abertzale HB, que fue el detonante de la expulsión por parte

13 En 1991 la LCR y el MC se unificaron formando izquierda Alternativa, cuya estructura en Andalucía adquirió el nombre de Acción Alternativa y funcionó como ONG. Posteriormente, algunos de sus militantes formaron Izquierda Anticapitalista. 
de la Ejecutiva de $\mathrm{CCOO}^{14}$. No obstante, desde el punto de vista de los militantes de Autonomía Obrera, la expulsión tiene más motivos de fondo: la crítica constante de la falta de democracia y el carácter conciliador de la dirección de CCOO por parte de estos militantes.

Así, estos trabajadores constituyeron su propia organización sindical, Autonomía Obrera, y prosiguieron su actividad logrando afiliar muchos trabajadores e incluso disputando la hegemonía de $\mathrm{CCOO}$ en los órganos de representación de los trabajadores en diversas empresas clave del municipio. AO afirma tener en la actualidad algo más de 1000 afiliados y entre 75 y 100 representantes sindicales en empresas de la Bahía de Cádiz. Actualmente tiene implantación en el Hospital Puerta del Mar (Cádiz), donde funcionan de manera unitaria con CGT, en el Ayuntamiento de Cádiz y sus empresas auxiliares (como Instituto Municipal de Deporte, limpieza viaria y recogida de residuos sólidos urbanos, Centro Náutico Elcano, limpieza de centros municipales, etc.), además de otras empresas como Intec Air-Aernnova o Altadis (Tabacalera). Una de sus líneas de actuación en los servicios públicos consiste en trabajar estrechamente entre el Comité de Empresa del Ayuntamiento y los representantes de los trabajadores de las empresas auxiliares, promoviendo la defensa de los derechos laborales, la organización sindical, el cumplimiento de los convenios y, en la medida de lo posible, firmando convenios de empresa que mejoren las condiciones establecidas en los convenios de ámbito superior.

En 2007 Autonomía Obrera se integró en el proyecto del Sindicato Andaluz de Trabajadores junto al SOC y otras organizaciones sindicales de menor tamaño. Así, sus representantes entraron a formar parte de la Permanente Nacional del SAT. Sin embargo, en 2012 el congreso de Autonomía Obrera decidió separarse del SAT, aunque manteniendo buenas relaciones. Esta decisión se debió a que percibieron que su puntos de vistas no estaban representados por la Dirección del SAT, en el que el peso de los líderes no permite una toma de decisiones colectiva, y, relacionado con lo anterior, la falta de estrategia adecuada para desarrollar una acción sindical dentro de las empresas.

\subsection{Sindicato Obrero Andaluz de la Construcción (SOAC)}

Este sindicato se formó en la provincia de Sevilla en el año 2001 por parte de sindicalistas de CCOO y UGT que se distanciaron de sus respectivas Ejecutivas por sentir que las decisiones perjudicaban a los intereses de la clase obrera y que había falta de democracia interna. Esta organización, con sede en Dos Hermanas y encabezada por su secretario general, Miguel Torres, afirma contar con 2000 afiliados en el sector de la construcción (aunque no tiene apenas representantes unitarios, principalmente debido a la alta temporalidad en la contratación en este sector). Su principal actividad va enfocada al cumplimiento del convenio colectivo

${ }^{14} A B C$ (Andalucía), 16 de julio de 1997, pág. 44. 
del sector en las empresas y a controlar las contrataciones. Para ello, movilizan a los trabajadores y presionan a la patronal para que contraten a trabajadores desempleados inscritos en sus bolsas de trabajo. De este modo se reparte equitativamente el trabajo y se evitan las "listas negras" que con frecuencia circulan entre los empresarios.

El SOAC mantiene estrechas relaciones con el Sindicato Andaluz de Trabajadores, si bien nunca se ha integrado. En 2008, por ejemplo, militantes de ambos sindicatos ocuparon una obra en el municipio de Camas (Sevilla) reclamando el cumplimiento del convenio y la contratación de personal desempleado.

\subsection{Coordinadora de Trabajadores de Andalucía (CTA)}

El sindicato Coordinadora de Trabajadores de Andalucía (CTA) nació en 2003 de la modificación de los estatutos del Sindicato Libre de Trabajadores de la Administración Pública, registrado en la Delegación de Córdoba de la Consejería de Trabajo de la Junta de Andalucía con fecha 31 de octubre de 1986. En 2003 también amplió su ámbito territorial de la provincia de Córdoba a Andalucía. El principal impulsor de dicho sindicato fue Francisco Moro, trabajador del Ayuntamiento de Córdoba, que había militado en el sindicato de servicios públicos de CNT y, posteriormente de CGT. Tras ser expulsado de ambas organizaciones constituyó la CTA.

La CTA se define como un sindicato de clase, anticapitalista que apuesta por las asambleas de base y la unidad obrera. Se encuentra federada a nivel estatal en la Coordinadora Sindical de Clase, una organización de sindicatos y federaciones de sindicatos de trabajadores que provienen de CCOO, UGT y CGT. El objetivo de esta federación es reconstruir el movimiento obrero para defender a los trabajadores desde una perspectiva anticapitalista. Ello explica, que buena parte de su material divulgativo (como comunicados, notas de prensa o páginas de internet) contenga fuertes críticas a los sindicatos mayoritarios.

Este sindicato tiene actualmente representantes en varias empresas andaluzas, especialmente en las provincias de Córdoba y Sevilla. En la provincia de Córdoba obtuvo 17 delegados en las elecciones sindicales en el periodo 2009-2011. Recientemente ha participado en conflictos laborales en empresas como Sadiel, laboratorios Pérez Jimenez, T-systems o Ayesa.

\subsection{Sindicato Democrático de los Trabajadores (SDT)}

El SDT es un pequeño sindicato de clase que se autodefine como "combativo, participativo, de movilización, solidario y anticapitalista". Su ámbito de actuación se limita a la ciudad de Málaga, donde no llegaron a tener más de una decena de delegados sindicales. Una de las características de SDT fue su activa participación en el intento de constituir un frente sindical alternativo a CCOO. Para ello, en 2005 constituyeron la Coordinadora Sindical Andaluza junto a los sindicatos Autonomía Obrera, CTA y SU. Ese mismo año esos cuatro sindicatos celebraron el primero de mayo en Córdoba de manera conjunta. En 2006 trataron de avanzar en la 
construcción de la coordinadora, contando además con el interés del Foro Sindical Andaluz. Organizaron varios encuentros con el objeto de coordinar a distintos sindicatos minoritarios implantados en Andalucía, la mayoría de ellos formados a partir de escisiones de sectores críticos de CCOO. El horizonte era constituir una confederación en la comunidad autónoma que aglutinara a todos los trabajadores y organizaciones sindicales radicales Tomaron como modelo la Coordinadora Sindical de Madrid, que forma parte de la Coordinadora de Sindicatos de Clase. La constitución del SAT en 2007, no obstante, paralizó la iniciativa de la Coordinadora, ya que algunas organizaciones, como AO y FAS, se integraron en el SAT. Hoy está prácticamente desaparecido.

\subsection{Sindicato de Comisiones de Base (CO.BAS)}

Co.bas se define como "sindicato de clase, asambleario, participativo, con independencia económica de los poderes públicos y privados, de lucha y confrontación con el sistema, donde son los trabajadores y las trabajadoras quienes toman las decisiones". Este sindicato se constituyó en noviembre de 2006 a partir, sobre todo, de militantes del "sector crítico" de CCOO que discrepaba del sector "oficialista" que copaba la dirección del sindicato. Las diferencias con la dirección giraban en torno a la práctica de firmar acuerdos con la patronal sin contar con la opinión de los trabajadores y la falta de combatividad a nivel de empresas. Además, los fundadores de Co.bas criticaban la falta de respeto a la pluralidad interna de la dirección de CCOO. Así que miembros del "sector crítico" constituyeron un sindicato alternativo a nivel estatal, contando con apoyo de militantes trotskistas de Corriente Roja y Red Roja.

Co.bas tiene una pequeña implantación en Cataluña, Madrid, Canarias, Extremadura y Andalucía. A nivel de sectores destaca su implantación en Telefónica, ayuntamientos de Córdoba y Santa Cruz de Tenerife, administración de Justicia de Canarias, ministerio de defensa de Canarias, etc. En Andalucía tan sólo tienen un núcleo en Córdoba y por no llegar a los 10 delegados en elecciones sindicales, no aparecen en los informes estadísticos de la Consejería de Empleo.

Con el objeto de revertir las dinámicas que dividen a la clase trabajadora, Co.bas mantiene una "vocación unitaria, de clase, reivindicativa", lo que entienden como la colaboración con movimientos sociales (como el antiglobalización y organizaciones como el Foro Social Mundial) y con redes como la "Xarxa contra despidos y la precariedad" (que actúa frente a cierres empresariales y realiza campañas en defensa de los derechos sociales). Además ha apostado por la unidad de acción con otras centrales sindicales alternativas, como el SOC de Andalucía, la Coordinadora Sindical de Madrid, entre otros.

\subsection{Sindicato Andaluz de Trabajadores (SAT)}

A pesar del éxito relativo del SOC, mantenerse en el contexto de creciente despoblación del medio agrario y de transformación de Andalucía en una economía postindustrial, exigía un importante ejercicio de renovación sindical. Esto es precisamente lo que se pretendía desde el SOC cuando se impulsó la creación del Sindi- 
cato Andaluz de Trabajadores. El 23 de septiembre de 2007 tuvo lugar la asamblea de constitución del Sindicato Andaluz de Trabajadores en la Universidad Pablo de Olavide de Sevilla. Al acto acudieron 500 delegados y observadores de diversas organizaciones políticas de la izquierda andaluza, muchas de ellas de carácter nacionalista andaluz: Partido Socialista Andaluz, Jaleo, Nación Andaluza, Los Verdes, Partido Comunista de los Pueblos de España (PCPE), Izquierda Unida, Partido Andalucista, y CUT (que a su vez forma parte de Izquierda Unida). También asistieron representantes de otras organizaciones sindicales con las que el SOC había estado trabajando estrechamente y que estaban invitadas a adherirse, como es el caso de Autonomía Obrera, un sindicato olivarero del Aljarafe, SUAT ${ }^{15}$ y Foro Sindical Andaluz ${ }^{16}$. El Sindicato Andaluz de Obreros de la Construcción y USTEA asistieron al congreso en calidad de invitados. A pesar de que se adhirieron cinco

15 Este sindicato fue creado en 1986 por militantes del Movimiento Comunista de Andalucía que abandonaron CCOO tras su enfrentamiento con la dirección del sindicato a causa de su activa implicación en las movilizaciones por el referéndum sobre la OTAN. Así, con la idea de impulsar un sindicalismo de clase, combativo y que defendiera los derechos nacionales de Andalucía, constituyeron su propio sindicato. Tomaron como modelo los sindicatos nacionalistas vascos ESK (también creado por militantes del Movimiento Comunista que habían abandonado CCOO) y LAB o las intersindicales gallega y canaria. Su principal impulsor fue Francisco Gabriel Lima Tirado, "Gabi", militante del MCA y posteriormente de Nación Andaluza. El SUAT sólo logró tener una presencia destacada en la provincia de Málaga, principalmente en Málaga y la Costa del Sol (sobre todo, en el sector de la hostelería). A mediados de los noventa trataron de constituir la Mesa por la Intersindical Andaluza junto al Sindicato de Obreros del Campo, el Sindicato Unitario de Huelva y USTEA (los sindicatos CGT y Autonomía Obrera habían colaborado en actos y reuniones pero no se llegaron a incorporar totalmente). El objetivo último de la MIA era establecer puentes entre estas organizaciones sindicales para construir una estructura confederal de sindicatos autónomos que representara al sindicalismo alternativo en Andalucía. Sin embargo, a principios de la década de 2000 la MIA no llegó a materializarse y las organizaciones que la integraban no llegaron a constituir la estructura federativa. El 15 de febrero de 2002, el secretario general del SUAT, "Gabi" murió asesinado en su domicilio en condiciones que aún no se han esclarecido. A partir de esta fecha, el SUAT perdió actividad y prácticamente desapareció hasta que en 2007 muchos de sus afiliados se integraron en el SAT.

${ }^{16}$ El Foro Sindical Andaluz (FSA) es un pequeño sindicato de ámbito andaluz impulsado por militantes del PCPA, la estructura del Partido Comunista de los Pueblos de España (PCPE) en Andalucía, un partido marxista-leninista constituido en 1984 por diversas escisiones del PCE. El FSA ha estado integrado como corriente en el Sindicato de Obreros del Campo. En 2007 se anexionó al SAT. En 2010, a raíz de diferencias con las actuaciones de Diego Cañamero y Juan Manuel Sánchez Gordillo, dirigentes del SAT, en una lucha por el cumplimiento del convenio en la Vega de Sevilla, el FSA se distancia del SAT. 
sindicatos, como veremos más adelante, el de mayor afiliación, Autonomía Obrera, terminaría por desmarcarse del proyecto. FSA también se distanciaría.

El SAT se presenta como un sindicato de clase y alternativo, a favor de la democracia directa y la participación, e independiente y autónomo de instituciones públicas y políticas. Además, combina la acción laboral con el objetivo de favorecer la soberanía nacional y el derecho de autodeterminación de Andalucía. Aunque desde su fundación el ritmo de crecimiento ha sido lento, poco a poco se ha ido implantando en algunos sectores y empresas (especialmente en Sevilla capital). Su principal característica es la práctica de un "sindicalismo de movimiento social", esto es, un sindicalismo que adopta algunas de las características de los movimientos sociales como el empleo de la acción directa —en ocasiones muy espectaculares - ; la defensa de objetivos que van más allá de lo meramente laboral e incluyen cuestiones como la defensa del medioambiente, de la igualdad de género, de la soberanía alimentaria o de la justicia social; y el establecimiento estrechos lazos con los movimientos sociales y las organizaciones comunitarias, como el movimiento okupa, el antimilitarista, el 15M o colectivos de inmigrantes. En el año 2012, el SAT experimentó una gran proyección mediática tras la expropiación de alimentos en dos supermercados. Esta proyección sirvió para afiliar a numerosos trabajadores y extenderse territorialmente. Sin embargo, la práctica de sindicalismo de movimiento social no ha ido acompañado por un avance similar en el ámbito de las empresas y centros de trabajo. Aunque puede decirse que el SAT es caso paradigmático de renovación sindical (Roca y Díaz 2013), no ha desarrollado estrategias adecuadas para ir restando la hegemonía de los sindicatos mayoritarios en las empresas. Afirman tener 20.000 afiliados, principalmente procedentes del SOC en el medio rural, y según la Consejería de Empleo obtuvieron 52 delegados en las elecciones sindicales en el periodo 2009-2011 (exclusivamente en las provincias de Cádiz y Sevilla, aunque con la salida de AO en 2012 puede que estas cifras se reduzcan significativamente en futuras elecciones).

En 2012 SAT, junto a CGT y CNT, han desarrollado líneas de colaboración en torno a lo que denominaron "Bloque Crítico". Tendiendo puentes entre los sindicatos radicales y nuevos movimientos sociales como el $15 \mathrm{M}$, pretenden impulsar movilizaciones masivas para contrarrestar los efectos negativos de la crisis económica y defender los derechos sociales. La rivalidad entre CGT y SAT por encabezar el sindicalismo radical en Andalucía se ha hecho patente en algunas movilizaciones de dicha coalición.

\section{Análisis: un enfoque sintético sobre la acción colectiva del sindicalismo radical}

Para comprender la pervivencia e implantación del sindicalismo radical en Andalucía, así como sus limitaciones, es preciso comparar los planteamientos, estrategias y evolución de las organizaciones con mayor implantación en la 
actualidad, que son, por orden de antigüedad: CNT, CGT, SAT, SU, USTEA, AO y SAT. En la siguiente tabla sintetizamos dicha información.

\section{Tabla 1. Comparación de planteamientos, estrategia y evolución de los princi- pales sindicatos radicales en Andalucía}

\begin{tabular}{|c|c|c|c|c|}
\hline Organización & Creación & Planteamientos & Estrategia & Evolución \\
\hline CNT & $\begin{array}{c}1910 \\
\text { (reconstituida } \\
\text { en década } \\
1970 \text { ) }\end{array}$ & $\begin{array}{l}\text {-Anarcosindicalismo } \\
\text {-Crítica sistema de } \\
\text { representación sindical } \\
\text { y pactos sociales }\end{array}$ & $\begin{array}{l}\text {-Acción sindical en } \\
\text { empresa a través de } \\
\text { Secciones Sindicales } \\
\text {-Alianza con otros } \\
\text { sindicatos (a partir de } \\
\text { diciembre de 2010). }\end{array}$ & $\begin{array}{l}\text {-Escisiones CGT 1980s } \\
\text {-Crecimiento a partir de } \\
\text { año } 2000 \text { (1.000 } \\
\text { afiliados en Andalucía) }\end{array}$ \\
\hline CGT & 1989 & $\begin{array}{l}\text {-Anarcosindicalismo } \\
\text {-Oposición a pactos } \\
\text { sociales }\end{array}$ & $\begin{array}{l}\text {-Acción sindical en la } \\
\text { empresa utilizando } \\
\text { elecciones sindicales. } \\
\text {-Estrategia activa de } \\
\text { implantación en sectores } \\
\text { (transporte, enseñan- } \\
\text { za...). } \\
\text {-Alianza con sindicalis- } \\
\text { mo minoritario (compe- } \\
\text { tencia con SAT por } \\
\text { liderar la coalición } \\
\text { "Bloque Critico). }\end{array}$ & $\begin{array}{l}\text {-Crecimiento ( } 10.000 \\
\text { afiliados en Andalucía) } \\
-522 \text { delegados en } \\
\text { Andalucía en elecciones } \\
\text { sindicales de 2009- } \\
2011 \text {. }\end{array}$ \\
\hline $\mathrm{SOC}$ & $\begin{array}{c}1975 / 76- \\
2007\end{array}$ & $\begin{array}{l}\text {-Reforma agraria } \\
\text {-Influencia marxista } \\
\text { revolucionaria, } \\
\text { comunista libertaria y } \\
\text { nacionalista andaluz } \\
\text {-Oposición a pactos } \\
\text { sociales }\end{array}$ & $\begin{array}{l}\text {-Movilizar a jornaleros } \\
\text { mediante acción directa. } \\
\text {-Gestión fondos PER } \\
\text {-Ocupa espacio político } \\
\text { no ocupado por PCE y } \\
\text { CCOO en campo } \\
\text { andaluz } \\
\text {-Fuertes liderazgos }\end{array}$ & $\begin{array}{l}\text {-Sale del CSUT en } 1980 \\
\text {-Mantiene } 20.000 \\
\text { afiliados } \\
\text {-2007 se convierte en el } \\
\text { SAT. }\end{array}$ \\
\hline SU & 1978 & $\begin{array}{l}\text {-Unir movilización } \\
\text { política y sindical. } \\
\text {-Oposición a pactos } \\
\text { sociales } \\
\text {-Influencia maoísta } \\
\text { (ORT) }\end{array}$ & $\begin{array}{l}\text {-Afiliar trabajadores y } \\
\text { delegados descontentos } \\
\text { de CCOO y UGT. } \\
\text {-Alianzas con sindicatos } \\
\text { minoritarios CGT y } \\
\text { SOC }\end{array}$ & $\begin{array}{l}\text {-Pérdida peso desde } \\
1980 . \\
\text {-Mantiene núcleo en } \\
\text { Huelva } \\
\text {-60 delegados en } \\
\text { elecciones sindicales } \\
2009-2011\end{array}$ \\
\hline USTEA & 1990 & $\begin{array}{l}\text {-Asamblearismo y de } \\
\text { izquierdas } \\
\text {-Fuertes influencias de } \\
\text { trotskistas (Izquierda } \\
\text { Anticapitalista) }\end{array}$ & $\begin{array}{l}\text {-Acción sindical en } \\
\text { localizado en educación } \\
\text { pública } \\
\text {-Extenderse administra- } \\
\text { ción pública y sanidad. } \\
\text {-Alianzas con SAT, SU } \\
\text { y otros sindicatos } \\
\text { radicales }\end{array}$ & $\begin{array}{l}\text {-Mayoritario en } \\
\text { profesorado de ense- } \\
\text { ñanza pública primaria } \\
\text { y secundaria } \\
\text {-232 delegados en } \\
\text { elecciones sindicales } \\
\text { 2009-2011 }\end{array}$ \\
\hline $\mathrm{AO}$ & 1997 & $\begin{array}{l}\text {-Critica falta democra- } \\
\text { cia interna CCOO y } \\
\text { pactos sociales } \\
\text {-Influencias de } \\
\text { izquierda radical (LR, } \\
\text { MC, IA y PCE(r)). }\end{array}$ & $\begin{array}{l}\text {-Acción sindical en } \\
\text { empresas sector público } \\
\text { de ámbito local. } \\
\text {-Intentos de coordina- } \\
\text { ción con otros sindicatos } \\
\text { minoritarios. }\end{array}$ & $\begin{array}{l}\text { - } 1.000 \text { afiliados y entre } \\
75 \text { y } 100 \text { delegados } \\
\text { sindicales en Bahía de } \\
\text { Cádiz } \\
\text {-2012 salida del SAT }\end{array}$ \\
\hline
\end{tabular}




\begin{tabular}{|c|c|c|c|c|}
\hline SAT & 2007 & $\begin{array}{l}\text {-Heredero del SOC } \\
\text { (marxismo revoluciona- } \\
\text { rio, comunismo } \\
\text { libertario y etnonacio- } \\
\text { nalismo) } \\
\text {-Oposición pactos } \\
\text { sociales }\end{array}$ & $\begin{array}{l}\text { "Sindicalismo de } \\
\text { movimiento social" } \\
\text { (alianza con movimien- } \\
\text { tos sociales y acción } \\
\text { directa espectacular). } \\
\text { - Ocupar espacio } \\
\text { sindical descontentos } \\
\text { con sindicatos mayorita- } \\
\text { rios } \\
\text {-Liderar frente sindical y } \\
\text { social radical: creación } \\
\text { "Bloque Crítico" en } \\
\text { 2011. }\end{array}$ & $\begin{array}{l}-20.000 \text { afiliados } \\
\text { - Crecimiento afiliación } \\
\text { y expansión territorial } \\
\text { (proyección acciones } \\
\text { espectaculares) } \\
\text { - } 52 \text { delegados en } \\
\text { elecciones sindicales } \\
\text { 2009-2011 (con salida } \\
\text { AO puede que haya } \\
\text { menos) }\end{array}$ \\
\hline
\end{tabular}

A partir de dicho cuadro se pueden identificar los ocho factores principales que explican la acción colectiva del sindicalismo radical andaluz. Tres de dichos factores proceden de la estructura de oportunidades políticas. El más importante de éstos la existencia de un sistema de relaciones laborales pluralista. En efecto, el marco legal permite constituir múltiples organizaciones sindicales y hace posible que éstas tengan acceso a la negociación colectiva si, en general, logran obtener determinadas cuotas electorales. En algunos casos, incluso a través de la presión directa o las secciones sindicales es posible negociar acuerdos en el ámbito de la empresa o centro de trabajo. La creciente desregulación y descentralización de la negociación colectiva que impone el marco normativo no hace más que fortalecer esta tendencia. En segundo lugar, el sindicalismo radical ocupa un espacio políticosindical que no han ocupado otras organizaciones de la izquierda. Esto es claro en el caso del SOC en el medio rural, pero también en el de las otras organizaciones como CGT, AO, SU y USTEA que reciben afiliación y militancia desencantada con los sindicatos mayoritarios. El actual contexto de deslegitimación de los sindicatos mayoritarios por los ataques de los medios de comunicación y los escándalos de corrupción, parecen estar favoreciendo este trasvase de afiliación. En tercer lugar, otro factor político que contribuye a la toma de posiciones del sindicalismo radical es la política de alianzas. Las continuos intentos de coordinación de sindicatos radicales (a través de la Mesa por la Intersindical Andaluza en la década de 1990, la Coordinadora Sindical Andaluz en 2005, el SAT en 2007 y el "Bloque Crítico" en 2012), el apoyo de partidos políticos de la izquierda radical (como PT, PCPE, IA o CUT) y la confluencia con nuevos movimientos sociales como el $15 \mathrm{M}$, han aumentado con frecuencia la proyección social y la capacidad de presión de estas organizaciones (Roca y Díaz 2013).

Otros tres factores que explican la presencia de este sindicalismo se ajustan a la teoría de la movilización de recursos. En el caso del SOC-SAT, al menos, la pervivencia de esta organización se debe a dos factores: el carácter aglutinante de sus líderes, actualmente Diego Cañamero y Juan Manuel Sánchez Gordillo, y el hecho de haber participado en la gestión del PER, que ha localizado al sindicato en una posición estratégica de acceso a recursos públicos para la población rural (Morales Ruiz 2000). Otro factor, que explica en mayor grado la implantación de sindicatos como CGT, USTEA, SU y AO, es el desarrollo de una actividad sindical 
muy localizada en sectores de actividad y empresas locales. Esto puede ilustrarse, por ejemplo, con el trabajo de CGT en el sector del transporte, dónde ha realizado un trabajo intensivo de afiliación, organización y movilización partiendo de las especificidades sectoriales.

Por último, aunque no menos importante, se han identificado dos factores que están relacionados con los procesos de enmarcamiento. El primer factor es la influencia de las ideologías radicales en estos sindicatos, pues el componente ideológico ha primado como motivación para la afiliación en un sector de los trabajadores reclutados por estas organizaciones (Letamendia 2013). Quizá CNT y SOC sean las organizaciones en las que este componente ha primado más tradicionalmente. El segundo factor es la conexión entre la acción sindical y las culturas del trabajo de determinadas empresas y sectores. Este es el caso que explica la presencia anarcosindicalista en la construcción naval gaditana (Florido, Roca y Gutierrez, 2013) o la hegemonía del SOC entre los jornaleros (Morales Ruiz 2000).

\section{Figura 1: Teorías de los movimientos sociales y factores explicativos del sindicalismo radical andaluz}

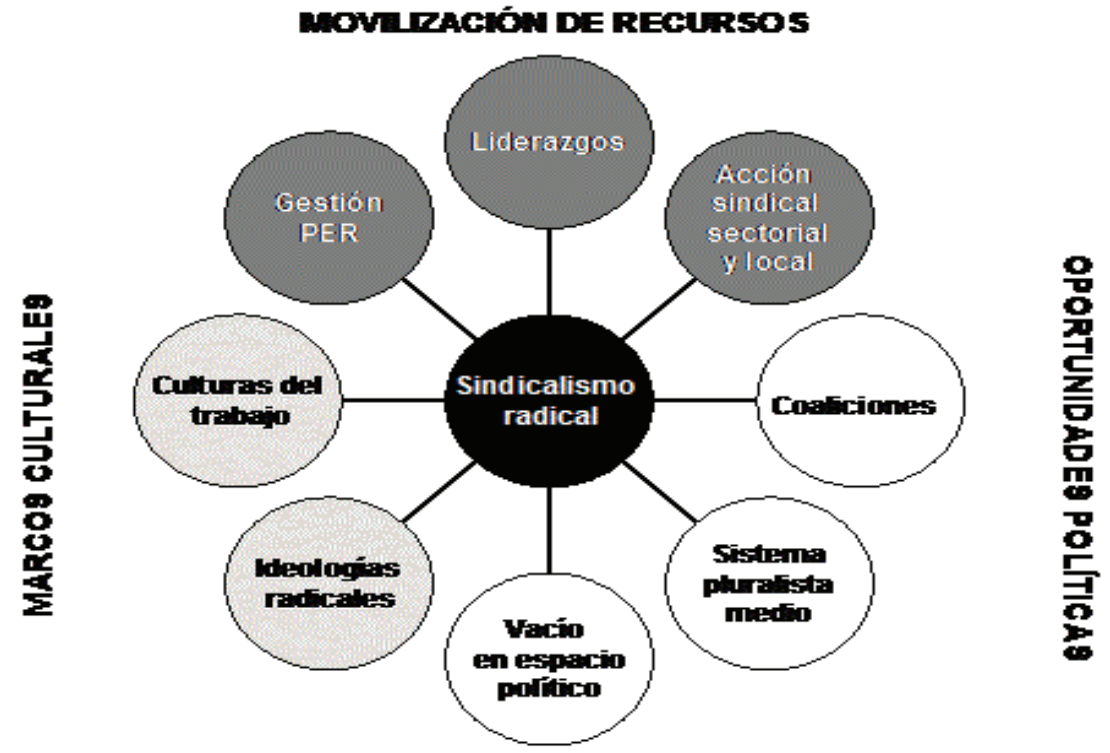

En resumen, es posible explicar la presencia de las organizaciones sindicales en Andalucía a partir de un enfoque sintético sobre la acción colectiva: los ocho factores principales por los que este sindicalismo pervive, e incluso aumenta de 
manera moderada su implantación, se ajustan tanto a movilización de recursos como a la estructura de oportunidades políticas y a la construcción de marcos culturales compartidos. Hay que matizar, como acertadamente ha señalado Letamendia (2013), que en la afiliación sindical coexisten motivaciones instrumentales (incluso en sindicatos radicales que logran implantarse en determinadas empresas y sectores). Todo ello refleja que la acción sindical es un fenómeno complejo que obedece a una múltiples de factores y debe ser estudiada desde varios enfoques.

\section{Conclusiones}

A lo largo de este artículo se ha reconstruido la accidentada trayectoria desde la Transición a la actualidad de las principales organizaciones sindicales ligadas a la izquierda radical. Se ha definido el sindicalismo radical como aquel influido por ideologías y organizaciones revolucionarias, en cuya acción colectiva predomina el conflicto sobre la negociación y la concertación, que rechaza las políticas de pactos sociales llevadas a cabo en España desde la Transición y que define su identidad por oposición a los sindicatos mayoritarios CCOO y UGT. Se han diferenciado dos grandes tradiciones en el sindicalismo radical: la anarcosindicalista, representada por los sindicatos CGT y CNT, y la marxista revolucionaria (en ocasiones combinada con nacionalismo andaluz), representada por organizaciones como SOC, USTEA, SU, AO, SOAC, CTA, Co.Bas, SAT y las escisiones de corrientes autogestionarias de la USO (CAT, CLAT o SAVID). La historia de estos sindicatos está plagada de escisiones y enfrentamientos internos, aunque también de episodios de lucha, victorias y crecimiento. Se puede destacar la alta fragmentación de este sindicalismo vinculado con la izquierda radical. La división no sólo obedece a las diferencias entre anarcosindicalistas y marxistas, sino que también ha sido favorecida por las mismas dinámicas sectarias que han seguido los partidos de izquierda radical, ya que muchas de estas organizaciones sindicales estaban impulsadas desde estos partidos como parte de su estrategia política. El mapa del sindicalismo radical en Andalucía, como se puede comprobar, está marcado por la fragmentación en múltiples organizaciones. Esta división hace que en Andalucía, a diferencia de Galicia o el País Vasco, no se haya desarrollado un movimiento sindical propio capaz de disputar la hegemonía de CCOO y UGT.

Tras exponer los planteamientos, estrategias y evolución de los principales sindicatos radicales en Andalucía, se han identificado los principales factores que explican la implantación de estas organizaciones sindicales en dicho territorio. Estos son: a) la existencia de liderazgos fuertes; b) la participación en la gestión del PER en el medio rural; c) el desarrollo de acción sindical muy focalizada en determinados sectores, empresas y territorios; d) la coincidencia con ciertas culturas del trabajo arraigadas en sectores y comunidades; e) el componente ideológico en un sector de la afiliación; f) la existencia de un sistema de relaciones laborales que permite pluralidad sindical y la descentralización de la negociación colectiva; g) el 
desarrollo de políticas de coaliciones con otros sindicatos radicales, partidos de izquierda y movimientos sociales; y h) la ocupación de un espacio político-sindical que otras formaciones de la izquierda han dejado vacío. Todos estos factores explican por qué pervive este sindicalismo radical y por qué en la actualidad está experimentando un moderado crecimiento. De este modo, se comprueba que la acción colectiva de estos sindicatos no puede explicarse exclusivamente a partir de una teoría particular sobre los movimientos sociales, sino que es precisa una perspectiva sintética. En otras palabras, la supervivencia de sindicatos radicales en Andalucía obedece tanto a la estructura de oportunidades políticas como al éxito de determinadas estrategias organizativas y al desarrollo de marcos culturales e ideológicos que favorecen su acción colectiva.

\section{Glosario}

AO: Autonomía Obrera.

ASC: Asociación Sindical de Conductores.

CAT: Colectivo Autónomo de Trabajadores.

CCOO: Comisiones Obreras.

CGT: Confederación General del Trabajo.

CIG: Confederación Intersindical Gallega.

CLAT: Confederación Libre y Autónoma de Trabajadores.

CNT: Confederación Nacional del Trabajo.

CO.BAS: Comisiones de Base.

CSC: Coordinadora Sindical de Clase.

CSUT: Confederación de Sindicatos Unitarios de Trabajadores.

CTA: Coordinadora de Trabajadores de Andalucía.

CUT: Colectivo de Unidad de los Trabajadores.

ELA: Eusko Langileen Alkartasuna.

ETA: Euskadi Ta Askatasuna.

FORA: Federación Obrera de la Región Argentina.

FSA: Foro Sindical Andaluz.

HB: Herri Batasuna.

HOAC: Hermandad Obrera de Acción Católica.

IA: Izquierda Anticapitalista.

JOC: Juventud Obrera Cristiana.

LAB: Langile Abertzaleen Batzordeak.

LCR: Liga Comunista Revolucionaria.

MCA: Movimiento Comunista de Andalucía.

ORT: Organización Revolucionaria de Trabajadores.

PCE: Partido Comunista de España.

PCE(i): Partido Comunista de España Internacional.

PCPA: Partido Comunista del Pueblo Andaluz.

PCPE: Partido Comunista de los Pueblos de España. 
PER: Plan de Empleo Rural.

PSOE: Partido Socialista Obrero Español.

PTE: Partido del Trabajo de España.

PTA: Partido del Trabajo de Andalucía.

SAC: Sindicato Andaluz de Conductores.

SAT: Sindicato Andaluz de Trabajadores.

SAVID: Sindicato Autónomo de la Vid.

SDT: Sindicato Democrático de Trabajadores.

SOAC: Sindicato Obrero Andaluz de la Construcción.

SOC: Sindicato de Obreros del Campo.

SOV: Sindicato de Oficios Varios.

STEs: Sindicatos de Trabajadores de Enseñanza.

SU: Sindicato Unitario.

SUAT: Sindicato Unitario Andaluz de Trabajadores.

UCSTE: Unión Confederal de Sindicatos de Trabajadores de la Enseñanza.

UGT: Unión General de Trabajadores.

USO: Unión Sindical Obrera.

USTEA: Unión Sindical de Trabajadores y Trabajadoras de Andalucía.

\section{Bibliografía}

Biddle, E.; Graeber, D. y Shukaitis, S. (eds.) (2009). Constituent imagination. Militant investigations. Collective Theorization. Thousand Oaks: Ak Press.

Castells, M. (1998). La era de la información: economía, sociedad y cultura, vol. 2, El poder de la identidad. Madrid: Alianza.

Cucó, J. (2004). Antropología urbana. Barcelona: Ariel.

Della Porta, D. (1998). Las motivaciones individuales en las organizaciones políticas clandestinas. En P. Ibarra y B. Tejerina (eds.), Los movimientos sociales. Transformaciones políticas y cambio cultural (pp 219-242). Madrid: Trotta.

Escobar, A. (1992). Culture, practice and politics. Anthropology and the study of social movements. Critique of Anthropology Vol. 12 Núm. 4, 395-432.

Feria Vázquez, P. J. (2005). Los sindicatos en la Huelva de la transición. Huelva en su Historia, Vol. 12, 151-172.

Florido, D., Roca, B. y Gutiérrez, J. L. (2013). Tightening the screws. Autonomy, collective action and violence in Puerto Real during the second shipbuilding Restructuring. Anthropological Quarterly, Vol. 86, Núm. 3, 891-922. 
García Calavia, M. A. (2012). Relaciones laborales en Europa Occidental. Valencia: Tirant lo blanch.

Gómez Oliver, M. (1993). Jornaleros andaluces, ¿una clase en extinción? Un análisis de la conflictividad campesina en los años 80. En E. Sevilla Guzmán, y M. González de Molina (Eds.), Ecología, campesinado e historia. (pp 375-407) Madrid: La Piqueta.

Harvey, D. (2007). Espacios del capital. Hacia una Geografia Crítica. Madrid: Akal.

Juris, J. (2009). Networking futures: the movements against corporate globalization. NC: Duke University Press.

Letamendia, F. (2013). Acción colectiva, sindicalismo, regulación local y regional. En Varios Autores, Sindicalismo en la empresa y el territorio. Una perspectiva anarcosindicalista e interdisciplinar. Zaragoza: Confederación Nacional del Trabajo.

Martín Artiles, A. (1987). Origen e Ideología de la USO. El Proyecto, núm. 1.

Martín Artiles, A. (2002). Actores y modelos de las relaciones laborales. Modelos comparados. Barcelona: Editorial UOC.

Martínez Foronda, A. (coord.) (2005). La conquista de la libertad. Historia de las Comisiones Obreras de Andalucia. 1962-2000. Puerto Real: FES-AHCCOOA.

McAdam, D. (1994). Cultura y movimientos sociales. En E. Laraña y J. Gusfield (eds.), Los nuevos movimientos sociales. De la ideología a la identidad. Madrid: CIS.

McAdam, D., McCarthy, J. y Zald, M. (eds.) (1996). Comparative perspectives on social movements: political opportunities, mobilizing structures and cultural framings. Cambridge: Cambridge University Press.

Melucci, A. (1994). Asumir un compromiso: identidad y movilización en los movimientos sociales. En M. Revilla (comp.), Movimientos sociales, acción e identidad. Madrid: Siglo XXI.

Montes Pita, L. (2009). Conflictos e ideología en la Unión Sindical Obrera antes y después de la escisión de 1980. Comunicación presentada en Historia de la transición en España: Sociedad y Movimientos sociales. IV Congreso de la Asociación de Historiadores del Presente, Almería, 2-6 de Noviembre 2009. 
Morales Ruiz, R. (2000). Aproximación a la historia del Sindicato de Obreros del Campo. En M. González de Molina (Ed.), La historia de Andalucía: a debate, vol. 2, (pp 179-199) Madrid: Anthropos.

Olson, M. (1963). The logic of collective action. Cambridge: Harvard Univ. Press.

Pérez de Guzmán, S. (2012). Negociación colectiva, acción sindical e intercambio político. Un planteamiento teórico apoyado en el análisis de las relaciones laborales en los astilleros de Cádiz. Papers: Revista de Sociología, Vol. 97, Núm. $4,773-794$.

Pérez Serrano, J. (2013). Orto y ocaso de la izquierda revolucionaria en España (1959-1994). En R. Quirosa-Cheyrouze (Ed.), Las organizaciones políticas en la Transición. Madrid: Biblioteca Nueva.

Piñeiro Blanca, J. (2009). El motor del cambio: asociacionismo y sociabilidad en la provincia de Cádiz, 1973-1983. En R. Quirosa Cheyrouze (Ed.), Historia de la Transición en España: sociedad y movimientos sociales (pp 345-378) Almería: Universidad de Almería.

Riechman, J. y Fernández Buey, F. (1994). Redes que dan libertad: Introducción a los nuevos movimientos sociales. Barcelona: Paidós.

Roca, B. y Díaz, I. (2013). De la tierra a los supermercados: el SAT como ejemplo de particularismo militante y de renovación sindical. Anuario del Conflicto Social 2012, 855-891.

Rogero, J. (2010). Movimientos de Renovación Pedagógica y Profesionalización Docente. Revista Latinoamericana de Educación inclusiva Vol. 4, Núm. 1, 141-166.

Solana Ruiz, José Luis (2000). Las clases sociales en Andalucía. Un recorrido socio-histórico. Gazeta de Antropología, Vol. 16, art. 08.

Talego, Félix (1996). Cultura jornalera, poder popular y liderazgo mesiánico. Antropología política de Marinaleda. Sevilla: Fundación Blas Infante.

Tarrow, S. (1998). El poder en movimiento. Los movimientos sociales, la acción colectiva y la política. Madrid: Alianza.

Vadillo, J. (2004). El anarquismo y anarcosindicalismo en la España de la Transición. En VV.AA. La transición a la democracia en España: actas de las VI Jornadas de Castilla-La Mancha sobre Investigación en Archivos. Guadalajara, 4-7 de noviembre 2003, Vol. 2, España: Asociación de Amigos del Archivo Histórico Provincial. 